\title{
A Docência On-line: Um Caso no Ensino de Teclado na Licenciatura em Música a Distância da UnB
}

\author{
Hermes Siqueira Bandeira Costa1, Paulo Roberto Affonso Marins*2
}

\begin{abstract}
1 Pesquisador, Instituto de Artes/Departamento de Música/ Universidade de Brasília. Campus Universitário Darcy Ribeiro SG-2 - Asa Norte - CEP 70910-900 - Brasília-DF, Brasil. hermes.siqueira@gmail.com

2 Professor Adjunto, Pesquisador, Instituto de Artes/Departamento de Música/ Universidade de Brasília. Campus Universitário Darcy Ribeiro SG-2 - Asa Norte - CEP 70910-900 - Brasília-DF, Brasil. pramarins@gmail.com
\end{abstract}

\section{Resumo}

Esta pesquisa teve por objetivo investigar como ocorre o ensino de teclado a distância, no âmbito do curso de licenciatura em Música a distância da Universidade de Brasília (UnB), assim como a utilização das tecnologias digitais nessa modalidade de ensino. A metodologia adotada foi o estudo de caso e os dados foram obtidos a partir de entrevistas semiestruturadas com os professores responsáveis pela criação das disciplinas de teclado do referido curso. Verificou-se que o ensino de teclado a distância ocorre prioritariamente de modo assíncrono entre professor e aluno por meio de materiais pedagógicos, produzidos previamente e veiculados por meio da combinação de diversas mídias digitais. $O$ emprego das tecnologias digitais no ensino a distância é massivo e sua utilização, por vezes, é aleatória. Apesar de a interação entre professor e aluno ocorrer majoritariamente assincronamente, em detrimento das formas síncronas de comunicação, o aprendizado do teclado é viável para a finalidade a que se dispõe: ter o instrumento de teclas para ensinar e fazer música.

Palavras-chave: Educação a distância; Educação musical a distância; Docência online; Tecnologias digitais. 


\title{
The Online Teaching: A Case in Teaching of Keyboard in Distance Music Degree of UnB
}

\begin{abstract}
This research aimed to investigate how teaching keyboard at distance occurs in Music distance education program at University of Brasília (UnB), as well as the use of digital technologies in this modality of teaching. The methodology adopted was the case study and data was obtained from semi-structured interviews with the teachers responsible for the elaboration of keyboard courses from the refered program. It was found that the teaching of keyboard at distance occurs primarily asynchronously between teacher and students and through the learning materials produced in advance and broadcasted through a combination of various digital media. The use of digital technologies is massive and its use sometimes is random. Although the interaction between teacher and student occurs mostly asynchronously to the detriment of synchronous forms of communication, learning keyboard is viable for the proposed goal: have keyboard instrument as a tool to teach and to make music.
\end{abstract}

Keywords: Distance education; Music distance education; On-line teaching; Digital technologies. 


\section{Introdução}

Apesar de não ser um fenômeno recente no país, a educação a distância mediada pela internet, ou educação on-line, modificou consideravelmente a percepção de educação, em especial a educação superior. A interação entre estudantes e professores não mais está restrita a um espaço físico-temporal determinado, limitado, pois é "impossível pensar que todas as atividades educativas previstas ocorram exclusivamente no espaço da escola, na sala de aula, diante de um professor" (Kenski, 2003, p. 2). O crescimento de propostas educacionais na Educação a Distância (EaD) tem sido favorecido pelo desenvolvimento das tecnologias digitais, ao permitir "(...) consultas com especialistas, (...) intercambiar opiniões, problemas ou propostas com outros usuários" (Litwin, 2001, p.17).

Outrossim, a EaD - através de iniciativas como o Sistema Universidade Aberta do Brasil - oferece cursos de nível superior a estudantes que têm dificuldade de acesso à formação universitária. Não obstante, verifica-se um desafio para os docentes que atuam na EaD na área de música, visto que, além das práticas inerentes à educação presencial, o ensino a distância requer maiores reflexões, em especial no tocante ao ensino de instrumentos musicais (como o teclado), cujo desafio consiste em promover o aprendizado por meio de recursos midiáticos que intentam suprir a ausência do professor em sala de aula.

A pesquisa relatada neste artigo teve por objetivo principal compreender o ensino do instrumento de teclado a distância por meio das perspectivas dos professores pesquisadores $^{1}$ do curso de Licenciatura em Música a Distância da Universidade de Brasília. Foram investigadas suas concepções e desafios sobre o ensino de instrumentos de teclado a distância. Atualmente três universidades públicas federais ofertam curso de Música na modalidade a distância, mediada pela internet: a Universidade Federal de São Carlos (UFSCar), a Universidade Federal do Rio Grande do Sul (UFGRS) e a Universidade de Brasília (UnB). Esta última foi escolhida como foco da referida pesquisa pelos seguintes motivos: 1) A UnB foi campo de atuação na prática on-line docente de um dos autores desta pesquisa, e 2) A UnB é uma instituição pioneira no tocante à oferta de cursos de educação a distância, tendo, desde a década de 1960 , realizado projetos para a utilização das tecnologias na educação e sendo - a 
partir da década de 1990 - participante nos processos de elaboração e implementação de políticas de EaD no Brasil (Pereira, Moraes, 2009).

Com a ampla difusão da educação a distância, percebe-se que "muito desses profissionais que hoje trabalham com EAD não tiveram uma formação 'formal' na área" (Litto, 2009, p. 14), ou seja, aprenderam na prática. Braga (2009) apontou em sua tese que o ensino de instrumento a distância apresenta desafios e gera desconfianças a respeito de sua eficácia. Mesmo alguns anos depois da afirmação de Braga (2009), os desafios continuam, porém a discussão deve ser direcionada em como maximizar o ensino e aprendizado de instrumentos a distância por meio da internet.

Portanto, surgiu o seguinte questionamento: como tem se configurado o ensino do instrumento de teclado em um curso de licenciatura em Música a distância? Diante dessa questão, outras subjacentes emergem: 1) Quais são as características docentes necessárias para o ensino de teclado a distância? 2) Como as tecnologias digitais são aplicadas no ensino de teclado a distância? Observou-se que o ensino de instrumentos a distância requer reflexões constantes, pois, assim como há um dinamismo no ensino presencial, a flexibilização e as inovações proporcionadas pelas Tecnologias da Informação e da Comunicação (TIC) fazem com que a educação on-line requeira do professor buscas constantes por renovações metodológicas e tecnológicas que melhor viabilizem o aprendizado para o aluno.

\section{O Ensino de Instrumento Musical a Distância}

Poucas são as pesquisas acadêmicas no Brasil que dissertam sobre ensino de instrumento musical a distância em contexto universitário. Isso reafirma a proposição de Braga (2009), que o ensino de instrumento a distância ainda é um tema pouco divulgado. As principais pesquisas acadêmicas com temáticas relacionadas ao ensino de instrumentos a distância no Brasil são: Braga (2009) e Westermann (2010), em que versam sobre o ensino de violão a distância; e Gohn (2011), que aborda o ensino de instrumentos percussivos. Especificamente sobre o ensino de teclado a distância, há a pesquisa de Domenici et al. (2012) que relata a experiência sobre a disciplina "Seminário Integrador de Teclado," do curso de Licenciatura em Música a Distância da UFRGS. 
Com uma temática direcionada ao estudo de violão via videoconferência, Braga (2009) descreveu o desenvolvimento de sua pesquisa, desde os estágios iniciais, com o planejamento do curso, até a fase de implementação. O projeto "Oficina de Violão a distância" teve por objetivo constatar quais padrões de interação eram mais pertinentes entre estudantes e professores durante o curso. Tais atividades foram realizadas por meio de videoconferências, além de encontros presenciais já estabelecidos. Segundo o autor, apesar das limitações técnicas do recurso utilizado para realizar as aulas, os resultados apontaram para uma efetiva aprendizagem musical, além de destacar uma maior interação entre professor e aluno, e aluno e aluno, num contexto de aprendizagem de um instrumento a distância.

Westermann (2010) trata da autonomia dos estudantes em um curso a distância. O autor abordou questões que influenciavam comportamentos autônomos dos alunos de violão, do curso de licenciatura em Música a distância da UFRGS. Esse curso, segundo o autor, é considerado diferenciado por estimular a "autonomia e a tomada de decisões por parte do aluno, mas também o limita, até certo ponto, pela existência de um currículo com objetivos educacionais" (Westermann, 2010, p. 30). De acordo com o autor, o objetivo do curso é formar instrumentistas acompanhadores capazes de utilizar o violão como uma ferramenta auxiliar para as aulas de música na educação básica,seja para acompanhar, cantar e acompanhar, assim como desenvolver habilidades próprias do instrumento: tocar peças solos, transposição e improvisação.

Sobre o ensino de instrumentos percussivos, Gohn (2011) descreve e justifica a utilização da disciplina de percussão no curso da UFSCar "por sua utilidade como ferramenta no desenvolvimento da musicalidade" (Gohn, 2011, p. 144), ao explorar as possibilidades sonoras de cada instrumento, atenção ao modo de tocar, na percepção dos diferentes timbres, bem como a percepção de aspectos rítmicos e sua relação entre som e movimento. De acordo com o autor, para a realização do ensino de percussão a distância, são necessários vídeos de boa qualidade para um contato síncrono - descritos na pesquisa como videoconferências - com os atores interagindo em tempo real.

Para Domenici et al. (2012, p.121), a experiência do supracitado curso de teclado a distância diferencia-se do tradicional ensino de piano por diversos motivos, 
dentre os quais: 1) ser estruturado sobre o ensino coletivo; 2) priorizar a memória e incentivar a execução de ouvido; 3) ter o teclado como colaborador ao acompanhar a voz humana; e 4) ser ensinado a distância por meio das TIC. Os resultados obtidos nesse curso da UFRGS apontaram para um "aproveitamento necessário, satisfatório e promissor deste modelo de ensino, que adota a EAD mediada por tecnologias da informação e comunicação", em que os objetivos, além da inserção dessa modalidade totalmente a distância, foram proporcionar uma ampliação das formas de estudo do presencial, "enriquecendo as perspectivas profissionais dos alunos", além da percepção da presença das TIC na educação, o que oferece "oportunidades de atuação e novas formas de inserção no mercado de trabalho, ampliando conhecimentos e modos de interação" (Domenici et al, 2012, p. 147-148).

Sem exaurir a discussão sobre a temática, infere-se que o ensino de instrumento ainda carece de amplas pesquisas, discussões entre os envolvidos nessa modalidade da educação musical a distância. Percebe-se que é algo complexo, diferenciado de uma disciplina estritamente teórica. Os desafios, além das questões pedagógicas - que sejam voltadas a atender ao público e às particularidades do ensino a distância enfrentam também seus entraves quando se trata de questões de ordem estrutural, tecnológica. Contextualizando-se para a área de instrumentos de teclas no curso da UnB, por exemplo, seriam necessários instrumentos com um mínimo de qualidade nos polos - unidades físicas de apoio presencial aos estudantes - como pianos ou teclados sensitivos ao toque (teclas com peso de piano) para que os alunos pudessem ter noções básicas de interpretação musical ou mesmo aprendizado de técnicas. As conexões de internet precisariam ser de melhor qualidade, a fim de possibilitar transmissão em tempo real com qualidade de de som e imagem.

\section{Metodologia}

Considerando os objetivos propostos, esta pesquisa delineou os processos de ensino de Teclado do curso de Música a distância da Universidade de Brasília por meio da perspectiva dos docentes que atuaram como professores pesquisadores das disciplinas. Além das concepções pedagógicas inerentes à educação on-line, verificouse como as tecnologias da informação e comunicação (TIC) foram utilizadas na docência virtual. 
Dadas as características da pesquisa de natureza qualitativa, na qual os dados emergem para se conhecer e compreender uma situação específica, através de experiências íntimas, em um determinado momento e lugar (Stake, 2011, p.101-102), realizou-se um estudo de caso sobre o ensino de teclado do curso de licenciatura em Música a distância da UnB por meio da perspectiva dos professores entrevistados. De acordo com Yin, o estudo de caso é uma "investigação empírica" que incita a uma profunda compreensão de um determinado fenômeno atual em seu contexto, em que "os limites entre o fenômeno e o contexto não são claramente evidentes", ou seja, nem sempre são "distinguíveis nas situações da vida real" (YIN, 2010, p.39-40). Para a coleta dos dados, foi utilizada a entrevista semiestruturada. Segundo Yin (2010), a entrevista é uma das fontes mais importantes de informações para o estudo de caso, de modo que as conversas fluam naturalmente, evitando-se assim as estruturas rígidas. De acordo com Gaskell (2002), é necessário preparar-se devidamente para a aplicação das entrevistas, o que inclui as seguintes etapas: preparação, planejamento, seleção dos entrevistados. Para o autor, o pesquisador deve considerar ainda duas questões: a especificação do tópico guia (o que perguntar) e a seleção dos entrevistados (a quem perguntar).

Para o desenvolvimento do tópico guia final, foram realizadas entrevistas piloto com dois professores que escreveram disciplinas de instrumento para o curso de Música a distância da UnB, a fim de que os dados pudessem se discutidos com a literatura apresentada. Ao todo, cinco foram os professores que desenvolveram as disciplinas de Teclado para o curso de Música a distância da UnB. Dentre os cinco contatados, apenas três professores se dispuseram a participar da investigação, o que foi fator determinante para a seleção destes professores.

Para identificação dos participantes, designaram-se os seguintes pseudônimos e suas respectivas siglas: Mateus - EPM (Entrevista do Professor Mateus); Nicolas - EPN (Entrevista do Professor Nicolas); e Lucas - EPL (Entrevista do Professor Lucas).

\section{Resultados e Discussão}

O processo de análise e categorização dos dados foi desenvolvido e ampliado em todas as etapas da pesquisa: na gênese dos roteiros das entrevistas, bem como no 
processo de análise das entrevistas piloto, durante a coleta, assim como enquanto os dados eram transcritos, com a finalidade de identificar e registrar ideias, códigos, temas semelhantes obtidos nas coletas dos dados para que passagens do texto pudessem ser combinadas. Esse processo, segundo Gibbs (2009), é utilizado para se exemplificar um mesmo fenômeno ou ideia e permitir que os dados possam ser examinados de forma estruturada, o que possibilita uma melhor organização dos mesmos (Gibbs, 2009).

As temáticas aqui abordadas relacionam-se diretamente com as questões de pesquisa: (1) Ensino de instrumento a distância; (2) Utilização de recursos midiáticos; (3) Características da docência virtual. Os dados compilados e analisados à luz das categorias que emergiram durante o processo de elaboração do guia da entrevista e durante as transcrições são mostrados nos próximos subitens.

\subsection{Ensino de Instrumento a Distância}

Neste tópico, procurou-se delinear a concepção dos professores sobre o ensino de teclado a distância, em como deveria ser um formato de aula de instrumento mediada pela internet. Uma aula de instrumento a distância seguiria o seguinte formato, segundo o professor Nicolas:

Você abre o computador, você tem lá toda a chamada daquele dia. Você vai ter uma apostila que você vai abrir e te trazer as instruções, todos os passos do que você vai fazer. Então você tem uma semana, sozinho, lá na sua casa. (...) Então ele tem uma apostila, ele tem vídeos, ele tem áudio, ele tem material de leitura em alguns casos, em alguns dias, e ele tem, nessa apostila, tudo discriminado, passo a passo o que ele tem que fazer. Então, você vai fazer isso, isso, isso e aí pede pra distribuir durante a semana a realização dessas atividades (EPN).

O professor Mateus exemplifica como seria o comando para o aluno, para que este realize as atividades propostas, seguindo determinadas etapas para a efetivação da aprendizagem, a qual deve ser realizada com alguma referência, seja por meio de um áudio, de uma grafia ou de um vídeo:

O aluno vai aprender um repertório. Como ele vai aprender o repertório sabendo-se que ele tem dificuldade da leitura ou qualquer aluno teria dificuldade da leitura? Eu faço com eles o que eu faria no presencial que 
é: onde estão as partes tecnicamente mais difíceis da peça? Que tipo de dificuldade técnica que é? Então, que tipo de preparação você dá pro aluno pra que quando ele chegue na peça, ele consiga tocar com menos problema ou mais fluentemente. Como eu resolvi isso? Eu peço pro aluno, eu faço essas etapas aqui, agora vocês vão tocar isso aqui e, então, eu faço no vídeo (EPM).

Segundo a concepção do professor Lucas, uma aula de instrumento seria semelhante a uma videoaula, em que o aluno tem à sua disposição uma partitura e um roteiro em que são descritos os passos a serem seguidos para a execução de determinada peça. Essa preparação, segundo o participante, é semelhante a uma aula do ensino presencial, em que o professor auxilia o aluno, preparando-o devidamente para a execução do repertório, antevendo as habilidades necessárias para aquela execução:

\begin{abstract}
Uma aula a distância, um exemplo aqui, seria uma vídeo-aula de uma peça; então, tem uma peça que eu gostaria que ele tocasse, só que eu não vou tocar pra ele sair tocando de ouvido. (...) Então, eu fazia uma preparação pra ele. Eu fazia uma videoaula ou uma explicação mesmo, um roteiro, de como ele iria fazer. (...) Os alunos fazem a gravação, o professor, tutor, identifica quais estão sendo as dificuldades pela gravação, se o aluno está errando é nota, é passagem, dedilhado, qual está sendo o problema; o supervisor auxilia o tutor nessa percepção dos problemas do aluno quanto a sua execução, o tutor responde, dando algumas soluções, algumas dicas, e o aluno refaz a peça, estuda novamente (EPL).
\end{abstract}

Com base nas respostas obtidas, infere-se que a interação entre professor e aluno é, prioritariamente, assíncrona em que o principal meio de interação é por meio dos materiais pedagógicos. O professor, nesse processo, torna-se um mediador entre o material pedagógico e o aluno. De acordo com Braga (2009, p.220), uma aula de música a distância pode ter bom funcionamento quando os alunos "são estimulados a interagirem e encontrarem suas próprias soluções com o professor auxiliando, pontualmente, dando algumas dicas e orientações somente quando isso for extremamente necessário". Para que a intervenção tenha um bom resultado, como afirma Braga (2009), faz-se necessário que esse tipo de interação esteja contemplado no planejamento do curso do professor conteudista, de modo que as atividades sejam direcionadas para que os alunos reflitam sobre suas ações. 
Para uma maior interação em tempo real, outros meios poderiam ser utilizados como as videoconferências; no entanto, devido a algumas dificuldades momentâneas como falha de áudio, conexão da internet, poderiam tornar essas atividades inviáveis, de acordo com os professores entrevistados, em especial para turmas com muitos alunos. O uso dessa ferramenta é ideal para turmas com número de alunos reduzidos (Braga, 2009). Gohn (2009) afirma que vídeos pré-gravados são opções viáveis para uma transposição do contato visual necessário em estudos musicais a distância como modo de suprir a não presença de aluno e professor num mesmo espaço e tempo.

Ensinar a distância uma prática musical prioritariamente visual é um desafio aos professores que estão envolvidos na educação musical nesse tipo de modalidade. Segundo Gohn (2009), o ensino de instrumentos musicais a distância encontra-se em seus estágios iniciais, assim, não há condições ideais adequadas, ainda, para essa prática. No entanto, tais desafios não impedem que uma proposta pedagógica consistente seja desenvolvida.

\subsection{Utilizações de Recursos Midiáticos}

Outro elemento a ser considerado na atuação docente da educação a distância refere-se a como as tecnologias e mídias digitais são utilizadas para veicular os conteúdos das disciplinas. O professor Nicolas discorreu sobre as mídias utilizadas e os objetivos que queria alcançar com essas ferramentas. Entretanto, por não ter acompanhado a aplicação da disciplina - que ficou a cargo de outro professor - o professor não soube responder se os objetivos foram alcançados conforme planejado.

Então, textos, vídeos que foram filmados lá em Brasília... Eu fui lá pra fazer as filmagens de vídeos demonstrativos de como deveriam ser resolvidos alguns problemas como, por exemplo, problemas técnicos com questões de cadências, como é que era a configuração das cadências no visual mesmo (EPN).

Em contrapartida ao realizado pelo professor Nicolas, em que os vídeos foram recursos amplamente utilizados, para o professor Lucas, os áudios foram os recursos mais utilizados.

Eu comecei com a parte escrita, utilizei poucos vídeos. O que eu mais utilizei e o que foi o mais interessante foram áudios, não... vídeo eu usei. Foram poucos vídeos. Os vídeos foram mais para as partes técnicas, 
mostrar a posição da mão, né?, mais nesse sentido que eu mostrei os vídeos (EPL).

Ainda de acordo com o professor Lucas, a parte escrita da disciplina foi planejada primeiramente, sendo as mídias utilizadas em segundo plano, pois para ele, "(...) os recursos, eles eram apenas... uma forma pra facilitar a aprendizagem do aluno, eles não eram primordiais, fundamentais, (...) eles eram pra facilitar" (EPL). Lucas discorre ainda que havia pensado, posteriormente ao planejamento da parte pedagógica de sua disciplina, quais recursos deveria utilizar, de modo a facilitar a aprendizagem do aluno, mesmo não sabendo como iria fazer ou mesmo "não tendo conhecimento, eu sabia que eu queria que fosse daquela forma, que seria mais fácil para o aluno, e que eu ia ter de buscar ajuda de alguma forma pra poder por esse sistema funcionar" (EPL).

Sobre como as mídias foram utilizadas nas disciplinas, o professor Mateus relatou que utilizou muitos textos, áudios, vídeos demonstrativos e, por vezes, vídeos em que os alunos participavam da música, tocando junto com os professores da videoaula. Esse aspecto pode ser relacionado com o conceito de interatividade de Belloni (2009), que - segundo a autora - significa a possibilidade de um usuário interagir com uma máquina.

No decorrer da fala sobre as tecnologias utilizadas, observa-se também, no professor Mateus, que o principal para a educação a distância é a pedagogia, sendo as ferramentas digitais instrumentos auxiliares nesse processo. O professor descreve que, no geral, ainda há problemas e limitações com as tecnologias utilizadas no curso a distância da UnB como qualidade de imagens ou vídeos postados no ambiente virtual ou sincronização entre imagem e som em uma videoconferência.

Assim, como apontada pela literatura, a discussão sobre seleção das mídias é ampla e complexa, em virtude da gama de programas computacionais e das constantes inovações dessas ferramentas tecnológicas. Como descritos por Moore e Kearsley (2007), os professores precisam ser criativos na escolha ou na combinação das mídias bem como identificar a tecnologia mais apropriada para a veiculação. Os autores afirmam que o professor não pode se ater somente a um tipo de mídia, que é preciso conhecer outros tipos de ferramentas tecnológicas e saber os pontos fortes e fracos de cada tecnologia digital, assim como estar preparado para eventuais contratempos. Para os autores, deve ser levado em conta o público-alvo, o tempo que demanda para os materiais serem produzidos e a confiabilidade das mídias. 
Longe de ser encerrada ou mesmo taxativa, na discussão da utilização e integração das diversas mídias na educação musical a distância, em especial no ensino de instrumentos, os professores relataram que, apesar das dificuldades encontradas em como operar determinada tecnologia, os objetivos das disciplinas foram alcançados. Entretanto, percebe-se que a utilização das mídias partiu das ferramentas disponíveis, principalmente daquelas que os professores conheciam no momento da criação das disciplinas, e deu-se de forma aleatória.

De acordo com as falas dos professores entrevistados, observa-se também que há uma necessidade de uma maior interação entre os participantes do ensino e aprendizagem de um instrumento, que é um elemento essencial para a prática musical. Uma dúvida que se apresenta é: como contornar essa situação e fazer com que a interação seja mais efetiva para o ensino de teclado? Essas e outras questões relacionadas às combinações de diversas mídias e tecnologias podem não ter soluções momentâneas, mas podem ser objeto de reflexões por parte dos professores envolvidos em conhecer e experimentar outras opções que também possam promover o aprendizado.

\subsection{Características da Docência Virtual}

Com este tópico procurou-se descrever as concepções dos docentes entrevistados a respeito das características que permeiam a atuação docente na educação on-line, quais seriam os requisitos e os desafios encontrados nessa modalidade de educação.

O professor Mateus relatou assim sua primeira experiência na docência virtual:

Criei uma disciplina sem nenhuma experiência, sem nunca saber o que que era. (...) Olhando hoje, eu penso que já teria que conhecer. Você faz bem alguma coisa quando você já conhece. Você se sente à vontade. Eu não conhecia nada. Eu nunca tinha visto uma disciplina a distância. Eu não sabia o que era Moodle. Eu não sabia como é que alguém podia aprender a distância. (...) a minha preocupação era: como uma pessoa vai poder, dispondo do computador, aprender a tocar um instrumento, a compreender música, a ler música (EPM). 
Outro professor, Nicolas, também destaca que nunca havia tido contato algum com o ensino a distância ou mesmo de quais seriam os conhecimentos básicos necessários para se atuar na $\mathrm{EaD}$ e pontua, ainda, que o importante para a universidade "era mais a elaboração do material pedagógico do que conhecimento de ensino a distância, dos procedimentos a distância, entendeu?" (EPN).

Percebeu-se que os professores, apesar do vasto conhecimento pedagógico, principalmente ao que se refere ao ensino de instrumento, nâo têm vivência com a educação a distância. Isso influenciou as atividades pedagógicas dos professores entrevistados em citações como falta de autonomia, como ensinar um instrumento online e quais os conhecimentos necessários que o professor deve ter para a educação a distância. Logo, espera-se que o professor nessa modalidade de ensino seja capaz de refletir sobre os aspectos de sua prática na docência on-line como, por exemplo, conhecer a realidade dos alunos que cursam uma graduação a distância; como ensinar e aprender a distância; ter mais contato com outros docentes que atuam nessa área, bem como conhecer outros cursos de graduação; em outras palavras, imergir na EaD.

Por meio dos relatos apresentados, bem como a literatura abordada sobre formação, há de se concordar com Belloni (2009, p. 87) quando diz que "qualquer melhoria ou inovação em educação passa necessariamente pela melhoria e inovação na formação de formadores". Os autores Moore e Kearsley (2007, p.172) destacam a importância de um treinamento de professores para a prática da educação a distância, o que abarca ao menos três componentes: 1) ampla prática com a mão na massa da divulgação das tecnologias envolvidas; 2) práticas com técnicas para humanizar um curso; 3) prática com técnicas para facilitar a participação do aluno (Moore, Kearsley, 2007, p.172) [grifo dos autores].

Inevitavelmente, educar a distância por meio da internet requer não somente os conhecimentos específicos sobre pedagogia musical. O ponto de vista que aqui propomos é que não basta adquirir conhecimentos técnicos para solucionar imediatamente algum eventual problema relacionado aos programas computacionais, o que facilmente pode ser amenizado com um curso realizado na área de informática. Por meio dos relatos, foi possível inferir que é necessário um curso de formação inicial e continuada para que o professor possa adquirir independência em relação à equipe gestora responsável pelo suporte e manutenção do ambiente virtual de aprendizagem. 
Com essa autonomia, o professor será capaz de manusear corretamente as ferramentas aplicadas no ambiente virtual de aprendizagem (AVA). Essa formação, além de suprir as necessidades imediatas dos professores, pode provocar uma reflexão de qual, como e o porquê de se utilizar determinada mídia para se alcançar os propósitos de uma disciplina, bem como incitar pesquisas de outras ferramentas tecnológicas que possibilitem alcançar os objetivos e facilitar a aprendizagem dos alunos.

\section{Considerações finais}

Conforme citado anteriormente, o objetivo desta pesquisa foi descrever e discutir a docência no ensino de teclado no curso de licenciatura em Música a distância da UnB. Diante do objetivo descrito, retomam-se também as questões de pesquisa: 1) Como tem se configurado o ensino do instrumento de teclado no curso de licenciatura em Música a distância da UnB? Conforme os relatos obtidos junto aos professores que participaram da pesquisa, pode-se inferir que o ensino de teclado a distância ocorre por meio da intensa utilização de tecnologias da informação e comunicação (TIC), as quais viabilizam a interatividade entre alunos e materiais didáticos devidamente planejados e produzidos pelos professores. Esses materiais pedagógicos produzidos normalmente combinam uma ou mais mídias e tecnologias. Em relação à interação entre aluno e professor, esta se dá - prioritariamente - de forma assíncrona, com extensa utilização de videoaulas. 2) Como as tecnologias digitais são aplicadas no ensino de teclado a distância? As tecnologias digitais não são utilizadas em função da pedagogia adotada pelo professor, mas sim aleatoriamente. As mídias produzidas são atreladas às crenças dos professores, bem como aos princípios que consideram importantes a fim de cumprir determinados objetivos e gerar competências. Infere-se que os recursos utilizados pelos professores estavam inseridos no âmbito das ferramentas digitais que conheciam e daquilo que aprenderam na prática. 3) Quais são as características docentes necessárias para o ensino de teclado a distância? Segundo os dados obtidos junto aos professores entrevistados, é necessário que o docente tenha conhecimentos específicos e pedagógicos de sua área de formação, em especial, no que tange à pedagogia do instrumento. Além da expertise de sua área, é necessário que ele saiba como planejar, desenvolver conteúdos e aplicar uma didática que seja 
voltada especificamente para o ensino on-line. Esse professor deve, também, conhecer o suficiente sobre a plataforma utilizada pela instituição à qual esteja vinculado, a fim de que o material produzido por ele esteja em conformidade com a estrutura que permita ao ambiente virtual de aprendizagem (AVA) configurar o curso. É necessário ainda conhecer quais as tecnologias digitais utilizadas em um curso a distância, como usá-las corretamente em sua prática on-line de modo que as ferramentas selecionadas sejam aplicadas a fim de facilitar o processo de ensino e aprendizagem.

Diante do exposto, constatou-se que os docentes entrevistados apresentaram dificuldades em manusear as mídias utilizadas nas disciplinas bem como no ambiente virtual em que trabalharam. Em parte, pelo fato de os docentes não possuírem uma vivência constante com as tecnologias digitais empregadas; por outro lado, por não terem tido um curso de formação inicial ou continuada na área tecnológica que os capacitasse para uma utilização mais crítica de tais ferramentas. A partir dessas observações, infere-se que uma formação continuada para esses docentes, para que saibam como, quando e por que utilizar as mídias e suas combinações, pode maximizar o ensino e a aprendizagem a distância. Em especial, uma formação continuada para o curso de licenciatura em Música a distância, devido às especificidades do próprio curso apontadas neste trabalho.

A partir dessas observações suscitadas, outras questões surgem: como ampliar o ensino de instrumentos a distância? Como as tecnologias podem ser mais bem aproveitadas na educação musical a distância?

Discussões sobre a viabilidade do ensino de instrumentos a distância devem ser evitadas, pois as pesquisas já realizadas comprovam a viabilidade da formação a distância de professores para atuar na educação básica e que tenham uma formação em algum instrumento, de modo a utilizá-lo como ferramenta de apoio nas aulas de música.

A educação musical a distância pode ser explorada em sua totalidade, pois é uma realidade concreta. Assim como é necessário um processo reflexivo quanto às tecnologias digitais a serem utilizadas, o docente precisa estar preparado para desenvolver uma prática pedagógica que atenda às especificidades do ensino de música a distância, pois, como abordado nesta pesquisa, essa área tem particularidades que a distinguem das demais. Há de se adotar uma postura e 
consciência de que a educação on-line não deve ser pautada somente nas oportunidades e desafios proporcionados pelas tecnologias digitais, mas em mudanças nas práticas pedagógicas, assim como na alteração de postura dos profissionais envolvidos, de modo que o ensino e a aprendizagem sejam desvinculados do ensino presencial e adquiram características próprias. Tais transformações poderão proporcionar significativas alterações no que tange aos aspectos organizacionais de um curso a distância e na qualificação de seus profissionais, de maneira que estes adequem seu ensino à realidade da educação a distância e de seus alunos, como também que as discussões mediadas pelos professores facilitem a construção do conhecimento.

Reitera-se a viabilidade dos cursos de licenciatura em música mediados pela internet, especialmente as disciplinas de instrumentos musicais, para que possam servir de referência àquelas instituições de ensino que queiram adotar o ensino de música a distância. Mais pesquisas que envolvam o ensino e aprendizagem de outros instrumentos musicais, bem como disciplinas teóricas, poderiam ser contempladas, possibilitando assim uma melhor consolidação das práticas educacionais da educação musical a distância.

\section{Agradecimentos}

Os autores agradecem à Coordenação de Pessoal de Nível Superior (CAPES) pela bolsa concedida entre Dezembro de 2011 e Outubro de 2013 para a realização desta pesquisa.

\section{Nota}

${ }^{1}$ Nomenclatura utilizada pela Coordenação de Pessoal de Nível Superior (CAPES) para designar os docentes autores de disciplinas para os cursos a distância.

\section{Referências bibliográficas}


Belloni, M. L. (2009). Educação a distância. 5.ed. - Campinas: Autores associados, 2009.

Braga, P.D.A. (2009). Oficina de violão: estrutura de ensino e padrões de interação em um curso coletivo a distância. Tese de Doutorado em Música. Universidade Federal da Bahia.

Brasil. (2009). Ministério da Educação. Projeto Político Pedagógico do curso de licenciatura em Música a distância da UnB. Brasília. Disponível em: www.ead.unb.br

Domeneci, C.L et al. (2012). Teclado no ensino de música a distância. In Nunes, H.S. (Org.) EAD na formação de professores de música. (pp. 119-148). Tubarão: Copiart.

Gaskell, G. Entrevistas individuais e grupais. (2002). In Bauer, M.W.; Gaskell, G. Pesquisa qualitativa com texto, imagem e som: um manual prático. (pp. 64-89). 10 ed. Tradução: Pedrinho A. Guareschi. 10 ed. Petrópolis: Vozes.

Gibbs, G. (2009). Análise de dados qualitativos. Tradução: Roberto Cataldo Costa. Porto Alegre: Artmed.

Gohn, D.M. (2003). Auto-aprendizagem musical: alternativas tecnológicas. São Paulo: Annablume.

Gohn, D.M. (2009). Educação Musical a Distância: propostas para ensino e aprendizagem de percussão. Tese de Doutorado em Ciências da Comunicação. Universidade de São Paulo.

Gohn, D.M. (2009b). EAD e o estudo de música. In: Litto, F.M., Formiga, M. (orgs.) Educação a distância: o estado da arte. (pp. 282-288). São Paulo: Pearson Education do Brasil.

Gohn, D.M. (2011). Educação musical a distância: abordagens e experiências. São Paulo: Cortez.

Kenski, V.M. (2003). Tecnologias e ensino presencial e a distância. Campinas - SP: Papirus. 
Kruger, S.E. (2010). A percepção de docentes sobre a formação continuada em educação musical, apoiada pela Educação a Distância, em um contexto orquestral. Tese de Doutorado em Educação. Pontifícia Universidade Católica de São Paulo.

Litto, F. M. (2009). O atual cenário internacional da EAD. In Litto, F.M., Formiga, M. (orgs.) Educação a distância: o estado da arte. (pp. 14-20). São Paulo: Pearson Education do Brasil.

Litwin, E. (2001). Educação a distância: temas para debate de uma nova agenda educativa. Porto Alegre: Artmed.

Moore, M. Kearsley, G. (2007). Educação a distância: uma visão integrada. Tradução: Roberto Gelman. São Paulo: Cengage Learning.

Pereira, E.W., Moraes, R.A. (2009). História da educação a distância e os desafios na formação de professores no Brasil. In Souza, A.M., Fiorentini, L.M.R., Rodrigues, M.A.M. (Orgs.). Educação superior a distância: Comunidade de Trabalho e Aprendizagem em Rede (CTAR) (pp. 65-90). Brasília. Disponível em: http://www.fe.unb.br/catedraunescoead/areas/menu/publicacoes/livrospublicados-pela-catedra/educacao-superior-a-distancia/livro-educacaosuperior-a-distancia-comunidade-de-trabalho-e-aprendizagem-em-rede-ctar

Stake, R. E. (2011). Pesquisa Qualitativa: estudando como as coisas funcionam. Tradução: Karla Reis. Porto Alegre: Penso.

Westermann, B. (2010). Fatores que influenciam a autonomia do aluno de violão em um curso de licenciatura em música a distância. Dissertação de Mestrado em Educação Musical. Universidade Federal da Bahia.

Yin, R. K. (2010). Estudo de caso: planejamento e métodos. $4^{\text {ed. }}$ Tradução: Ana Thorel. Porto Alegre: Bookman. 